\title{
Study on the Application of Chinese Traditional Patterns in Modern Graphic Design
}

\author{
Lili Sun \\ School of Design and Art \\ Harbin University of Commerce \\ Harbin, China 150028
}

\begin{abstract}
The paper has discussed the relationship of Chinese traditional pattern and modern graphic design, the composition form and meanings of Chinese traditional patterns, and the organic combination of Chinese traditional pattern and modern design concepts. The author believes that we should lay emphasis on the inheritance and development of Chinese traditional patterns in modern graphic design. Only by grasping the implied meanings and the cultural connotations of patterns on the basis of recreation of Chinese traditional patterns, can we design works with national characteristics, and better develop Chinese excellent traditional culture.
\end{abstract}

Keywords-national traditional pattern; inheritance; application; development; graphic design

\section{INTRODUCTION}

The domestic design education completely accepted Western design concept which is based on three compositions after 1980s, so outstanding national traditional pattern resources have been stranded. Pattern design is relegated to secondary position and even it is disused. In the nearly 20 years, graphic design in China develops rapidly. Some outstanding designers have creatively and organically combine national traditional patterns with modern design concept, and created many excellent works. Graphic design in China keeps forging ahead in the nationality exploration road. Through the long historical accumulation, Chinese national cultural art gradually forms patterns and decorations with typical cultural connotation, and rich graphic resources, including figures, plants, animals and totems. This vast field could provide modern design with rich and adequate nutrition.

The broad and profound Chinese traditional culture has a significant influence on Chinese traditional patterns. Pattern is the best visual element to embody cultural connotation. Chinese traditional pattern has a long history, which is presented and continued by paper-cut, murals, furniture, ceramics, painting masks, printmaking, stone carvings, clothing and other folk carriers. The primitive totems and auspicious symbols of the Ming and Qing Dynasties have reflected the aesthetic function and decorative function of Chinese traditional pattern. The design is harmony, moderate and plain, and the style is implicit and restrained, which is in line with Chinese traditional humanism, view of nature and view of philosophy. It shows profound and charming national temperament, and embodies the unique ideological connotation and aesthetic ideas of Chinese nation. However, the western mainstream graphic design attracts viewers and meets their aesthetic taste and let them identify and accept certain information through certain aesthetic picture combining with patterning, color, character and other elements. In the commercial culture, graphic design has the economic value and practical function. It pursues visual tension and impact and direct and pure visual communication and appeal. In the promotion of the pragmatism philosophy and commercial culture, business-centered design mode has made fruitful achievements, and it almost has become a universal schema. In addition to their different functions, their history backgrounds and communication media are also very different.

However, Chinese traditional pattern and modern graphic design have something in common: first, Chinese traditional pattern and modern graphic design are all two-dimensional spatial category. Secondly, the basic elements of Chinese traditional pattern and modern graphic design contain patterning, color and composition form. Finally, the two are forms with certain meaning and connotation for the purpose of information transmission. It doubtlessly will bring a new fresh Chinese flavor to modern design style to organically combine pattern elements with national characteristics with modern design.

\section{ANALYSIS OF THE NATIONAL TRADITIONAL PATTERNS}

In the modern graphic design, understanding and grasping the composition and the implied meaning of Chinese traditional pattern can help designer correctly select and properly apply national traditional patterns.

Firstly, feel the "beauty" of the national traditional patterns. Outstanding national traditional pattern resources include simple primitive painted pottery pattern, mysterious bronze patterns of Shang Dynasty and Zhou Dynasty, romantic lacquer patterns of the Spring and Autumn and the Warring States period, antique decorative patterns of Qin Dynasty and Han Dynasty, decorative paintings of the Wei and Jin Dynasties, complicated auspicious patterns of Ming and Qing Dynasties and so on. Through the appreciation of these colorful national traditional patterns, can we fully experience the unique aesthetic characteristics of the national traditional patterns in different periods and find the aesthetic rules. Thus, it stimulates people's interest in traditional national patterns and scholars to explore traditional patterns. 
Secondly, master the "composition" of the national traditional pattern. Analyze the "composition" of national traditional pattern, grasp the composition rule of national traditional pattern, and upgrade the understanding of national traditional pattern to the rational level, and improve our sensitivity on its form. On the basis of studying and mastering the composition changes and rules of these patterns, we can create modern patterning with Chinese characteristics.

Modern patterning is composed by two parts, modeling element and composition element. The modeling element includes point, line and plane. The composition element includes gradient, segmentation, repetition, emission and aggregation, contrast and unity, rhythm, scale and other form of laws. The combination of modeling element and composition makes relationship intertwined, but the ordered arrangement naturally produces infinite imagination. Chinese traditional pattern follows the principle of composition change, forming endlessly changeable abstract structure and modeling. The composition rules of Chinese traditional patterns generally include the combination form, the free form, the suitable form and Taiji pattern and so on.

Finally, understand the "implied meaning" of national traditional pattern. National traditional patterns make good use of rich implication and imagination to replace the realistic depiction of figure, and make figures into artistic images with symbolic meaning, and thus cleverly subtly form characteristic quality with beautiful meaning and profound implication, leaving people a strong and deep impression. The "meaning" hidden in Chinese traditional patterns is the key reason why people are infatuated with it. To understand the connotation and meaning of national traditional patterns needs us to combine the historical backgrounds, including politics, economy, culture, concepts and other factors.

Chinese tradition always adores harmony, so Chinese people praise harmony highly. They believe harmony brings wealth and a harmonious family will prosper. For thousands of years, Chinese traditional pattern has such fresh vitality. It has a close relationship with the auspicious concept. According to their different meanings, national traditional pattern generally is divided into three types, the blessing type, the cultural meaning type and spiritual yearning type. Patterns of the blessing type symbolizes long life and peace, happiness and lucky. It uses metonymy, metaphor, pun, symbolism, homophony and other methods to endow animals and plants with auspicious meanings, and express their good wishes. For example, Chicken symbolizes lucky; bat symbolizes happiness; peach symbolizes long life; fish symbolizes richness. Through these meanings, they gain spiritual safety and pleasure. Patterns of the cultural meaning type use modeling to express peace and health, and endless social and cultural concepts. For example, "Taiji", "the Eight Diagrams", "cloud pattern", "Ruyi" and "joyful reunion" have the characteristics of balance, vividness and completeness. Viewing from personal psychological dependence, these patterns represent balance, vividness and completeness, and extend to social and cultural demand. Patterns of the spiritual yearning type use poetic articles and personalization symbols to express inner pursuit and spiritual yearnings, such as "three durable plants of winter" (pine , bamboo and plum blossom), and four gentlemen (plum blossom, orchid, bamboo and chrysanthemum).

\section{THE SPECIFIC APPLICATION OF CHINESE TRADITIONAL PATTERNS IN MODERN GRAPHIC DESIGN}

First of all, create new patterning through pattern simplification. The modeling forms of Chinese traditional pattern mainly focus on conformal completeness and decoration, and care the echo, comity and interpenetration relationship between patterns. The composition process follows the integral and symmetrical skeleton style, such as Sudoku and intersected figure, as well as the most primitive and basic Chinese auspicious symbol - Taiji pattern. In Chinese traditional patterns, there are many extremely general and strongly artistic patterns. They can be directly applied in works. But designers shouldn't apply them mechanically. For delicate and complex national traditional patterns, designers should boldly simplify and generalize them according to design. It is to extract its essence by using modeling rule and design principle. It is also a process to gradually excavate connotation and modify pattern, maintain its spiritual connotation and romantic charm on the basis of understanding the pattern. In this process, Chinese traditional patterns can inspire designers to make creative design and be the highlight of design.

Second, combine the form borrowing and modern design concept. The form borrowing includes two types. One is to combine national traditional pattern elements with modern design concept. It is a combination of the past and the present. The other is to integrate the national traditional pattern elements with Western graphic composition techniques. It is an integration of Chinese and Western elements. These two types are inclusive. For this reason, the reasonable composition and artful conception are very important. Japanese Designer Shibuya Katsuhiko has borrowed Chinese traditional "Shihe pattern" as modern package design element in the cosmetic box of "Shiseido". For another example, "double phoenix", the station logo of Phoenix Satellite Chinese Channel, is also extremely with Chinese traditional cultural characteristics. It has borrowed the phoenix pattern of primitive painted pottery, and used modern design concept. With the structure form of "joyful reunion", it reflects a profound cultural background. The two phoenix patterns are face to face with swirling wings, which are extremely vivid. It has reflected the characteristics of modern media.

Last, use the extended connotation to express the implication of national traditional pattern. Throughout the ages, the reason why people repeatedly trace one pattern is that it has an appearance with aesthetic meaning, and contains deep symbolic significance. The patterning is the external form of internal meaning. From the development and extended meaning of these patterns, we can feel that the evolution of "pattern" in each historical period is not a thorough negation of its original "motif", but a new form with new aesthetic concepts, so as to enrich and expand these motifs continuously. The national traditional pattern has profound meanings. If designers are able to use the implied meanings of these patterns, their design works will give out unique Chinese charm. It is the key for Chinese design to keep a foothold in 
the world. The above-mentioned traditional auspicious patterns contain diversified auspicious meanings, which is an accumulated national culture in the thousand years of long history, and a common wealth of the ancient and modern people. These auspicious patterns are beloved by people, so they are easily accepted by people. We should positively use the traditional culture to transmit rich and beautiful connotations and well convey information through modern design. In modern graphic design, the application of "patterning" and "meaning" of national traditional patterns is an important way to inherit and develop national traditional patterns. On the basis of the profound comprehension of the national traditional pattern art spirit, we can combine Western design concepts, embrace everything that is useful and constantly seek the integrating point of tradition and modern culture.

If we want to grasp the "meaning" of national traditional pattern, we need to grasp its "connotation". In order to convey the charm of pattern, designs shall be endowed with deepness and meaning. It needs us to deeply perceive traditional cultures and apply them in design. In order to broaden vision and deepen the understanding on the relationship between national traditional pattern and modern design, it is very important to appreciate works of modern excellent designers, such as, Kan Tai Keung, Alan Chan, Chen Shaohua, Lu Jingren et al. They are advocator and practitioners to use Chinese traditional culture in modern design. Most of their works make full use of traditional cultural elements, and combine with Western modern design concept. These outstanding works will bring us great inspiration and guidance.

The recreation of national traditional patterns will bring modern design with new vitality. The thing we really inherit is the essence of national traditional pattern, thus we can use our national forms to transmit the "meaning" and "charm" of our national patterns. It is our constant pursuit to apply traditional symbols skillfully.

\section{REFERENCES}

[1] Jiang Diankun. Reconstruction of Traditional Patterns in Modern Graphic Design. Master's Degree Thesis of Northeast Normal University, 2007.

[2] $\mathrm{Li} \mathrm{Li}$. Application of Chinese Traditional Auspicious Patterns in Modern Graphic Design. Master's Degree Thesis of Beijing Institute of Technology, 2008.

[3] Huang Weiwen. Application of Traditional Patterns in Modern Graphic Design. Packaging Engineering, 2014 (18): 82 - 85.

[4] Fu Ling, Wang Zhenwei. Traditional Patterns and Graphic Design. China Packaging Industry, 2014 (22): 53 - 53. 